\title{
Fossil primate challenges Ida's place
}

\section{Controversial German specimen is related to lemurs, not humans, analysis of an Egyptian find suggests.}

A 37-million-year-old fossil primate from Egypt, described today in Nature ${ }^{1}$, moves a controversial German fossil known as Ida out of the human lineage.

Teeth and ankle bones of the new Egyptian specimen show that the 47-million-year-old Ida, formally called Darwinius masillae, is not in the lineage of early apes and monkeys (haplorhines), but instead belongs to ancestors (adapiforms) of today's lemurs and lorises.

"Ida is as far away from the human lineage as you can get and still be considered a primate," says Christopher Beard, a palaeoanthropologist at the Carnegie Museum of Natural History in Pittsburgh, Pennsylvania, who was not involved in either research team.

Philip Gingerich of the University of Michigan in Ann Arbor, a lead author on the Ida report, said in an e-mail that his group continues to stand by its analysis that their specimen is closer to monkeys and apes than to lemurs. Led by Jørn Hurum, a researcher at Oslo's Natural History Museum, the team promoted the near-complete Ida skeleton as a missing link in human evolution, although the formal publication, in PLoS ONE ${ }^{2}$, didn't go that far. Adapiforms are not in the human lineage.

After years of secret deals to purchase the skeleton and prepare the fossil, Ida was launched in May in a lavish entertainment campaign $^{3}$ that included a book and film projects. New York City mayor Michael Bloomberg was enlisted for her unveiling at the American Museum of Natural History.

Ida's skeleton is the earliest such primate specimen found, and offers great insight into the development of these animals long before apes and humans shared a last common ancestor - estimated at 8 million to 10 million years ago. But immediately upon publication, the conclusions about Ida were roundly criticized ${ }^{4}$ by leading early-primate researchers, including Erik Seiffert of Stony Brook University in New

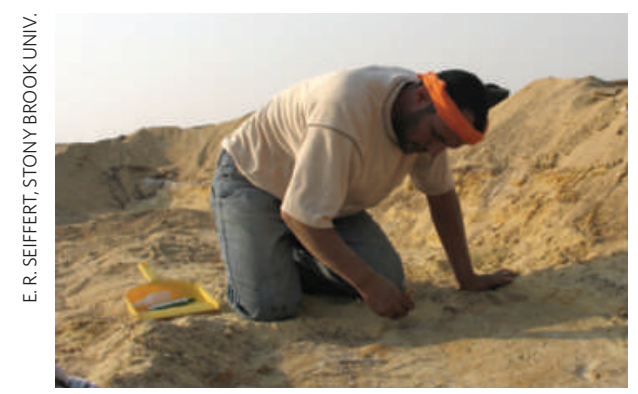

Years of painstaking research revealed the fossil.

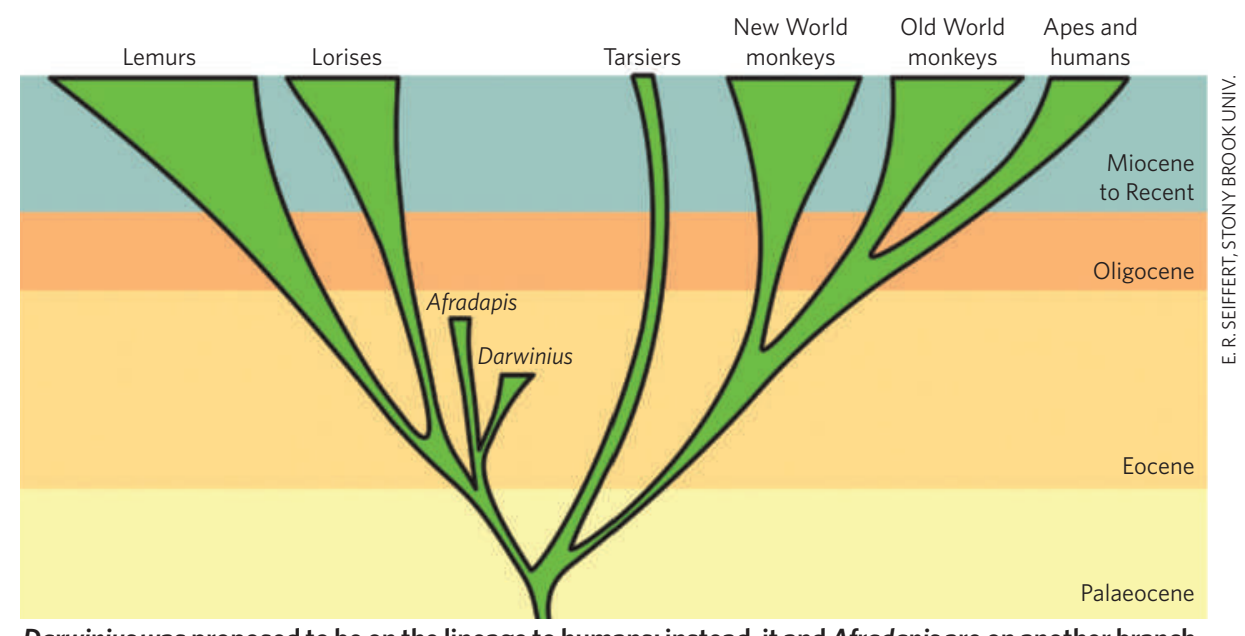

Darwinius was proposed to be on the lineage to humans; instead, it and Afradapis are on another branch.

York and Elwyn Simons of Duke University in Durham, North Carolina.

Seiffert and Simons are co-authors of today's Nature report on the new species, Afradapis longicristatus.

Probing sand-buried sediments about 60 kilometres southwest of Cairo, in 2000 their team found the first specimens of a series of teeth and jaw bones. Using delicate brushes, over the years they uncovered the near-complete dentition, and were close to submitting it for publication when Ida rocketed into the headlines, even garnering its own Google logo.

Seiffert says that, given Ida's wonderful preservation and undisputed age, his team needed to include it in their planned publication analysis, which examined more than 117 living and extinct primate species records. This analysis not only defined the context for Afradapis, but put both Afradapis and Darwinius in the adapiform lineage.

As part of this added analysis, Seiffert travelled to Gingerich's Michigan lab last spring to examine a high-resolution cast of Ida. Seiffert says that characteristics said to link Ida to haplorhines weren't supportable. Key among these was an ankle bone, the talus, which Gingerich's group reported as straight-sided, like that of a haplorhine species. "It is not possible to say this because the specimen is damaged and the bone obscured," says Seiffert.

Gingerich says the differing interpretation may arise because a cast, not the original, was examined. He noted that his group is running computerized tomography scans of Ida to more clearly describe the fossil's feet and hands. In addition, Hurum says, "Darwinius as a skeleton is much more complete than Afradapis, and Darwinius shows additional haplorhine characteristics not preserved here".

In the Nature report, the authors describe dental characteristics that place their species as an adapiform. The last molar is relatively long from front to back, and the front cusp of each molar is missing - both adapiform traits. "We discovered a close relative of Ida," says Seiffert. "But they both are in the lemur lineage."

Contacted at the dig site in the Fayum Depression region late last week, Seiffert said the team had uncovered more ankle bones of their species that confirm their Nature diagnosis. The team now has nearly 40 Afradapis individuals. The animal was the largest primate of the time, weighing nearly 3 kilograms and thriving on insects and fruit.

But their animal doesn't have a nickname. No popular-science book has been published. And no film project is planned. It seems unlikely that Afradapis will get its own Google logo. Rex Dalton

1. Seiffert, E. R. et al. Nature 461, 1118-1121 (2009).

2. Franzen, J. L. et al. PLoS ONE 4, e5723 (2009).

3. Nature 459, 484 (2009).

4. Simons, E. L. et al. Nature 460, 456 (2009).'

\section{ANNOUNCEMENT}

Alison Abbott, Nature's senior European correspondent, has been awarded the Euroscience Foundation's European senior Science Writers' Award for 2009. Abbott received the $€ 3,000$ (US $\$ 4,500$ ) prize "for being continuously committed to high quality science and research policy journalism" at a 14 October ceremony at the University for Music and Drama in Hanover, Germany. 